American J. of Engineering and Applied Sciences 3 (1): 7-14, 2010

ISSN 1941-7020

(C) 2010 Science Publications

\title{
Production Scheduling for Dispatching Ready Mixed Concrete Trucks Using Bee Colony Optimization
}

\author{
Sakchai Srichandum and Thammasak Rujirayanyong \\ Department of Civil and Environmental Engineering, Rangsit University, Pathum-Thani, 12000, Thailand
}

\begin{abstract}
Problem statement: This study proposed a systematic model of delivering Ready Mixed Concrete (RMC) that optimizes the schedule of dispatching RMC trucks. Approach: Firstly, the factors that impact the RMC delivery process are analyzed. Secondly, a model based on Bee Colony Optimization (BCO) was developed in order to find the best dispatching schedule that minimize the total waiting time of RMC trucks at construction sites. Results: To demonstrate its efficiency, the $\mathrm{BCO}$ algorithm was applied to solve two dispatching RMC problems. The results obtained from the $\mathrm{BCO}$ are compared to those achieved from the conventional approaches i.e., Genetic Algorithm (GA) and Tabu Search (TS) algorithm. Conclusion/Recommendations: The experimental results showed that the BCO approach can quickly generate efficient and flexible solutions to dispatch RMC trucks. Furthermore, the obtained results had higher quality solution efficiently and faster computational time than those obtained from the conventional approaches.
\end{abstract}

Key words: Bee colony optimization, meta-heuristic algorithm, optimization, RMC trucks dispatching

\section{INTRODUCTION}

In modern construction, Ready Mixed Concrete (RMC) is one of the most popular building materials in construction industry. RMC is prepared generally in a concrete batch plant and ingredient materials for concrete production are weighed and mixed by automated devices consistent with the request of the construction sites. Accordingly, RMC is convenient for all types and all sizes of construction. RMC has several benefits compared to concrete prepared by conventional methods. Regrettably, RMC cannot stock at a batch plant, because of the quick solidifying nature of the concrete. RMC usually needs to be poured within approximately $1-2 \mathrm{~h}$ after being produced by the RMC batch plant that limits the service area of the RMC batch plant. Consequently, RMC industry is concern about production scheduling and truck dispatching. Production scheduling and truck dispatching can be done manually by experienced staffs. Effective production scheduling and efficient truck dispatching are considerable issues for a carrier's RMC plant and construction site management, requiring the carrier to address both timeliness and flexibility, while satisfying construction site operating constraints. For that reason, the distribution of RMC is a complex problem in logistics and combinatorial optimization.

\section{MATERIALS AND METHODS}

There have been only few studies in the literature dedicated to RMC production or truck dispatching scheduling. Several models for simulation the construction operation have been developed (Cheng and Feng, 2003; Lu et al., 2003; Zayed and Halpin, 2001). Furthermore, the efficient and flexible models based on optimization techniques were proposed (Naso et al., 2004; Zayed and Minkarah, 2004; Yan et al., 2008). In the past decade, various natural inspired algorithms were developed, such as Simulated Annealing (SA) (Aarts and Korst, 1989), Genetic Algorithm (GA) (Holland, 1975; Goldberg, 1989; Gen and Cheng, 1999), Tabu Search (TS) (Glover, 1989; 1990; Bland and Dawson, 1991) algorithm and Particle Swarm Optimization (PSO) (Kennedy and Eberhart, 1995; Eberhart and Kennedy, 1995), They are probabilistic heuristic algorithms and have been successfully used to address combinatorial optimization problem. These algorithms can provide better solution in comparison to classical algorithms. A branch of natural inspired algorithms known as Swarm Intelligence (SI) is focused on insect behaviors in order to develop some metaheuristics, i.e., Ant Colony Optimization (ACO) (Dorigo et al., 1996), PSO. Bee Colony Optimization (BCO) was proposed by Karaboga (2005). It is relatively a new member of SI. The BCO algorithm mimics the food foraging behavior of swarms of honey bees. Honey bees use several mechanisms like waggle dance to find optimal location of food sources and to search new ones. This algorithm is a very simple and robust stochastic optimization algorithm.

Corresponding Author: Sakchai Srichandum, Department of Civil and Environmental Engineering, Rangsit University, Pathum-Thani, 12000, Thailand 
Effectively and efficiently delivering RMC to construction sites is an important issue to the batch plant manager. The manager has to consider both timeliness and flexibility to develop an efficient schedule of dispatching RMC trucks, which balances the operations at the construction sites and the batch plant. The existing dispatching schedule mainly depends on the experiences and preferences of the dispatcher. A systematic approach to tackle stated problem has seldom been taken due to the complexity and uncertainty involved within the dispatching process. Consequently, there is a need to develop a systematic model that optimizes the schedule of dispatching RMC trucks. Therefore, this study develops a model that combines RMC production scheduling and truck dispatching together. The objective is to minimize the total waiting time of RMC trucks at construction sites and to satisfy the needs of RMC from different construction sites based on $\mathrm{BCO}$ algorithm. The simulation results obtained from the BCO are compared to those achieved from the conventional approaches i.e., GA and TS algorithm.

Principle and modeling of RMC dispatching: The RMC supply process can be divided into five major components (Feng et al., 2004) which are Material production, Production loading, Truck transport, RMC placement and Truck return as shown in Fig. 1.

The RMC production and placement activities must be connected with trucks to form an operation cycle. In practice, truck service is limited in a given area; the trucks must be carefully dispatched in order to avoid concrete setting. Therefore, RMC production scheduling and truck dispatching are not only affect delivery efficiency, but also the operating cost.

Factors affected the schedule of dispatching RMC trucks: The traveling time between the RMC batch plant and the construction site is determined by the distance between the two locations, so are the speed of the RMC truck and the traffic condition. Therefore, it is not easy to predict the exact traveling time required to deliver RMC to different construction sites. In this study, the average traveling time between the batch plant and the construction site can be estimated from the Google earth software.

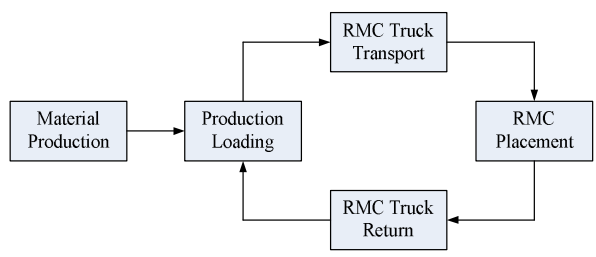

Fig. 1: RMC operating procedure
The duration of pouring RMC at the construction site depends on the types of the construction activities, which could affect the dispatching interval between assigning RMC trucks to the same construction site

The number of deliveries needed to a construction site depends on the quantity of RMC, loading capacity of the truck and the road bearing limit permitted by the regulation.

Dispatching model: This is systematic model that breaks the dispatching model into four parts which are input parameters, decision variables, constraints and system output.

Input parameters: The input parameters include the number of RMC deliveries, traveling time, pouring duration, mixing duration and allowable buffer duration. The allowable buffer duration presents the maximum duration that the construction site can wait for the arrival of RMC truck.

Decision variables: The sequence of assigning each RMC truck to the different construction sites is defined as "dispatching sequence". Only the dispatching sequence of RMC trucks is considered as the decision variable which decides the dispatching schedule in this model.

Constraints: The continuously pouring requirement restricts the duration that the construction site waits for the arrivals of the RMC truck is smaller than the allowable buffer duration. This constraint is applied to eliminating the infeasible dispatching schedules.

System output: The goal of developing an efficient schedule of dispatching RMC trucks is to minimize the total waiting time of RMC trucks at construction sites without breaking off the operation of pouring concrete. Consequently, the total duration that the RMC trucks wait at the construction sites and the duration that construction sites are idle for the arrivals of RMC trucks can be identified. From the development of the RMC dispatching model above, it is clear that the efficiency of the RMC dispatching schedule depends on the dispatching sequence of the RMC trucks. The dispatching sequence of the RMC trucks is the permutation of the RMC deliveries required by different construction sites, which is similar to the typical traveling salesman problem (TSP) except that the construction sites are visited more than once. As it can be expected, the solution space could be explosive if the designated construction sites and the required RMC deliveries increase. The total solution space of the dispatching schedules can be determined by: 
Am. J. Engg. \& Applied Sci., 3 (1): 7-14, 2010

$\mathrm{TS}=\frac{\left(\sum_{\mathrm{j}=1}^{\mathrm{m}} \mathrm{k}_{\mathrm{j}}\right) !}{\prod_{\mathrm{j}=1}^{\mathrm{m}}\left(\mathrm{k}_{\mathrm{j}} !\right)}$

Where:

$\mathrm{TS}=$ The total solution space

$\mathrm{k}_{\mathrm{j}}=$ The required number of RMC deliveries

$\mathrm{m}=$ The number of construction sites that request RMC deliveries

For example, if there are only five construction sites and each site requires four-truck deliveries, the total solution space of dispatching schedules is $3.05 \times 10^{11}(=(4+4+4+4+4) ! /(4 ! 4 ! 4 ! 4 ! 4 !))$, which can not be efficiently solved by using traditional optimization techniques. Therefore, a $\mathrm{BCO}$ is developed to find the best dispatching schedule of the RMC trucks because of its quick converge on the optimal or the sub-optimal solutions. In the following, the development of the $\mathrm{BCO}$ for optimizing the schedule of dispatching RMC trucks is explained in details. Figure 2 shows the systematic model of the dispatching RMC deliveries.

\section{Bee colony optimization for dispatching RMC} trucks:

Principle of BCO: The BCO algorithm was proposed by Karaboga (2005) to optimize numerical problems. The algorithm mimics the food foraging behavior of swarms of honey bees. Honey bees use several mechanisms like waggle dance to optimally locate food sources and to search new ones. This makes them a good candidate for developing new intelligent search algorithms.

In $\mathrm{BCO}$ algorithm, the colony of artificial bees contains two groups of bees, which are scout and employed bees. The scout bees have responsibility is to find a new food source, while responsibility of employed bees is to determine a food source within the neighborhood of the food sources in their memory and share their information with other bees within the hive.

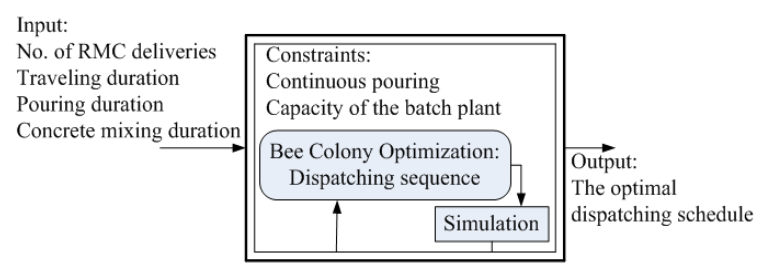

Fig. 2: System model of dispatching RMC delivery
Procedure of BCO: As mentioned, the BCO is an optimization algorithm inspired by the natural foraging behavior of honey bees to find the optimal solution. The algorithm requires a number of parameters to be set, namely: $\mathrm{NC}$ is number of iteration, $\mathrm{n}_{\mathrm{s}}$ is number of scout bees, $m$ is number of sites selected out of $n_{s}$ visited sites, e is number of best sites out of m selected sites, nep is number of bees recruited for best e sites, $\mathrm{nsp}$ is number of bees recruited for the other (m-e) selected sites, ngh is initial size of patches which includes site and its neighborhood and stopping criterion.

The process of the BCO algorithm can be summarized as follows:

Step 1: Generate randomly the initial populations of $n$ scout bees. These initial populations must be feasible candidate solutions that satisfy the constraints. Set NC $=0$.

Step 2: Evaluate the fitness value of the initial populations.

Step 3: Select $\mathrm{m}$ best solutions for neighborhood search.

Step 4: Separated the $\mathrm{m}$ best solutions to two groups, the first group have e best solutions and another group has m-e best solutions.

Step 5: Determine the size of neighborhood search of each best solutions (ngh).

Step 6: Generate solutions around the selected solutions within neighborhood size.

Step 7: Select the fittest solution from each patch.

Step 8: Check the stopping criterion. If satisfied, terminate the search, else $\mathrm{NC}=\mathrm{NC}+1$.

Step 9: Assign the n-m population to generate new solutions. Go to Step 2.

In step 3 and 4 , bees that have the highest fitness value are chosen as "selected bees" and sites visited by them are chosen for neighborhood search. Then, in step 5 and 6 , the algorithm conducts searches in the neighborhood of the selected sites, assigning more bees to search near to the best e sites. The bees can be chosen directly according to the fitness values associated with the sites they are visiting. Alternatively, the fitness values are used to determine the probability of the bees being selected. Searching in the neighborhood of the best e sites which represent more promising solutions is made more detailed by recruiting more bees to follow them than the other selected bees. Together with scouting, this differential recruitment is a key operation of the BCO. However, in step 7, for each patch only the bee with the highest fitness value will be selected to form the next bee population. In nature, 
there is no such a restriction. This restriction is introduced here to reduce the number of points to be explored. In step 9, the remaining bees in the population are assigned randomly around the search space scouting for new potential solutions. These steps are repeated until a stopping criterion is met.

\section{Components and processes:}

Solution structure: The solution structure used in this study is designed so that all permutations can be represented and evaluated. Firstly, the length of the solution is defined as the total number of the RMC trucks that will be dispatched from the RMC plant. For example, if there are three construction sites that require three, four and five trucks respectively to deliver RMC in the close period of time, the total length of the solution would be 12, the sum of three, four and five. Secondly, the random value representation is used in this study to avoid the infeasible and illegal solutions generated within the evolution process. Figure 3 shows the process of decoding a solution with random value representation. This solution represents the dispatching sequence involved with construction site 1, 2 and 3 , which requires three, four and five trucks respectively to deliver RMC. In Fig. 3, "Site ID" denotes each bit's corresponding construction site. The dispatching sequence is determined according to each bit's "Site ID" and its corresponding random number in ascending order. For example, the smallest random number of the bits is 0.03 and the corresponding "Site ID" is 2, which indicates the dispatching sequence starting with assigning the RMC truck to the construction site 2 . Consequently, the dispatching sequence of the string is decoded to $2,3,2,2,1,3,3,3,1,1,2$ and 3 .

Fitness value: The fitness value of a dispatching schedule is determined by minimizing the total duration that the RMC trucks wait at the construction sites, which can be determined by the simulation process. The process of pouring concrete at construction site could be interrupted if the duration that construction site waits for the arrival of the RMC truck is longer than the allowable buffer duration; hence a penalty function is used to represent the level of violation.

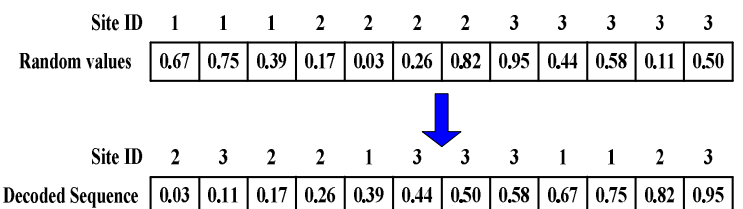

Fig. 3: Example of the solution structure
A simple example of determining the fitness value of a dispatching schedule is described in the following. The same example as described in solution structure is used for demonstration. In addition, the batch plant owns five RMC trucks and the duration of mixing concrete (MD) is $2 \mathrm{~min} \mathrm{~m}^{-3}$. The information of dispatching operation is listed in Table 1.

In practical, the distance $(\mathrm{km})$ from the batch plant to the construction site can find by using the Google Earth. In this study, the average speed of RMC truck traveling from the batch plant to the construction site is $20 \mathrm{~km} \mathrm{~h}^{-1}$. Therefore, the traveling time from the batch plant to the construction site $\mathrm{j}$ (in $\mathrm{min}$ ), $\mathrm{TDG}_{\mathrm{j}}$ can calculate from Eq. 2. The average speed of RMC truck returning back from the construction site to the batch plant is $30 \mathrm{~km} \mathrm{~h}^{-1}$. Therefore, the returning time from construction site $\mathrm{j}$ to the batch plant (in min), $\mathrm{TDB}_{\mathrm{j}}$ can calculate from Eq. 3:

$\mathrm{TDG}_{\mathrm{j}}=\mathrm{D}_{\mathrm{j}} \times 3$

$\mathrm{TDB}_{\mathrm{j}}=\mathrm{D}_{\mathrm{j}} \times 2$

$D_{j}=$ Distance from the batch plant to the construction site $(\mathrm{km})$

The calculated results of $\mathrm{CD}_{\mathrm{j}}, \mathrm{MD}_{\mathrm{j}}, \mathrm{TDG}_{\mathrm{j}}$ and $\mathrm{TDB}_{\mathrm{j}}$ are shown in Table 2.

Step 1: Determine the ideal departing time of each RMC truck. The ideal dispatching process of the batch plant is the process that RMC truck leaves the plant as soon as concrete is loaded.

Table 1: Information of the dispatching operation

\begin{tabular}{llllrll}
\hline Site & $\mathrm{SCT}_{\mathrm{j}}$ & $\mathrm{R}_{\mathrm{j}}\left(\mathrm{m}^{3}\right)$ & $\mathrm{PT}_{\mathrm{j}}$ & $\mathrm{D}_{\mathrm{j}}$ & $\mathrm{ABD}_{\mathrm{j}}$ & $\mathrm{ABT}_{\mathrm{j}}$ \\
\hline 1 & $08: 00$ & 14 & Floor & 10 & 45 & 45 \\
2 & $08: 00$ & 18 & Beam & 8 & 45 & 45 \\
3 & $08: 30$ & 24 & Column & 15 & 45 & 45 \\
Capacity of the batch plant & 5 Trucks & & & & & \\
Max load of trucks & $5 \mathrm{~m}^{3}$ & & & & & \\
\hline
\end{tabular}

$\mathrm{j}$ : The index of construction site; $\mathrm{SCT}_{\mathrm{j}}$ : Start pouring time of the construction site $\mathrm{j}$ (in $24 \mathrm{~h}$ format); $\mathrm{R}_{\mathrm{j}}$ : The required amount of the $\mathrm{RMC}\left(\mathrm{m}^{3}\right) ; \mathrm{PT}_{\mathrm{j}}$ : The placement type i.e., floor $\left(4 \mathrm{~min} \mathrm{~m}^{-3}\right)$, beam $\left(7 \mathrm{~min} \mathrm{~m}^{-3}\right)$ and column $\left(9 \mathrm{~min} \mathrm{~m}^{-3}\right) ; \mathrm{ABD}_{\mathrm{j}}$ : The allowable buffer duration of construction site $\mathrm{j}(\mathrm{min}) ; \mathrm{ABT}_{\mathrm{j}}$ : The allowable buffer duration of RMC truck (min); $\mathrm{CD}_{\mathrm{j}}$ : Pouring duration of the construction site $\mathrm{j}(\mathrm{min})$ where $\mathrm{CD}_{\mathrm{j}}=\mathrm{R}_{\mathrm{j}} \times \mathrm{PT}_{\mathrm{j}}$ : $\mathrm{k}_{\mathrm{j}}$ : The required $\mathrm{RMC}$ truck deliveries for the construction site $\mathrm{j}$. $\mathrm{R}_{\mathrm{j}}$ : maximum load of truck

Table 2: Calculated results of parameters

\begin{tabular}{lrrrrrrrrrrrr}
\hline $\mathrm{i}$ & 1 & 2 & 3 & 4 & 5 & 6 & 7 & 8 & 9 & 10 & 11 & 12 \\
$\mathrm{j}$ & 1 & 1 & 1 & 2 & 2 & 2 & 2 & 3 & 3 & 3 & 3 & 3 \\
$\mathrm{k}$ & 1 & 2 & 3 & 1 & 2 & 3 & 4 & 1 & 2 & 3 & 4 & 5 \\
Delivery & 5 & 5 & 4 & 5 & 5 & 5 & 3 & 5 & 5 & 5 & 5 & 4 \\
$\mathrm{CDj}$ & 20 & 20 & 16 & 35 & 35 & 35 & 21 & 45 & 45 & 45 & 45 & 36 \\
$\mathrm{MDj}$ & 10 & 10 & 8 & 10 & 10 & 10 & 6 & 10 & 10 & 10 & 10 & 8 \\
$\mathrm{TDGj}$ & 30 & 30 & 30 & 24 & 24 & 24 & 24 & 45 & 45 & 45 & 45 & 45 \\
$\mathrm{TDBj}$ & 20 & 20 & 20 & 16 & 16 & 16 & 16 & 30 & 30 & 30 & 30 & 30 \\
\hline
\end{tabular}


Am. J. Engg. \& Applied Sci., 3 (1): 7-14, 2010

Table 3: Earliest departing time of RMC trucks

FDT Min [08:00-00:30, 08:00-00:24, 08:30-00:45] = 07:30

$\begin{array}{lllllllllllll}\mathrm{i} & 1 & 2 & 3 & 4 & 5 & 6 & 7 & 8 & 9 & 10 & 11 & 12\end{array}$

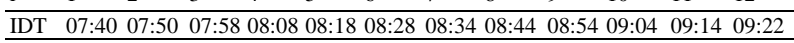

Table 4: Dispatching sequence generated by the BCO

\begin{tabular}{llllllllllll}
\hline 2 & 1 & 3 & 1 & 3 & 2 & 3 & 3 & 2 & 1 & 3 & 2 \\
\hline
\end{tabular}

Therefore, the ideal departing time of each RMC truck as shown in Table 3 is determined by Eq. 4 and 5:

$$
\begin{aligned}
& \mathrm{FDT}=\min _{\mathrm{j}=1}^{\mathrm{m}}\left[\mathrm{SCT}_{\mathrm{j}}-\mathrm{TDG}_{\mathrm{j}}\right] \\
& \mathrm{IDT}_{\mathrm{i}}=\left\{\begin{array}{cc}
\mathrm{FDT} & \mathrm{i}=1 \\
\mathrm{IDT}_{\mathrm{i}-1}+\mathrm{MD}_{\text {index }(\mathrm{i})}, & \mathrm{i}=2 \sim \mathrm{N}
\end{array}\right. \\
& \mathrm{N}=\sum_{\mathrm{j}=1}^{\mathrm{m}} \mathrm{k}_{\mathrm{j}}
\end{aligned}
$$

Where:

FDT $=$ The departing time of the first dispatched RMC truck

$\mathrm{IDT}_{\mathrm{i}}=$ The ideal departing time of $\mathrm{i}^{\text {th }}$ dispatched RMC truck

$\mathrm{MD}_{\text {index(i) }}=$ The duration of mixing concrete

$\mathrm{i}=$ The dispatched order of the RMC truck

$\mathrm{m}=$ The number of construction sites that request RMC deliveries

$\mathrm{k}_{\mathrm{j}} \quad=$ The required $\mathrm{RMC}$ deliveries of the construction site $\mathrm{j}$

$\mathrm{N}$ = The total number of the RMC deliveries for all construction sites

Step 2: Simulate the process of dispatching RMC trucks. The ideal departing time of each RMC truck can be determined by step 1 . However, the capacity of the batch plant is limited to five trucks; it is possible that the batch plant can not delivery RMC because no trucks are back. Therefore, only the departing time of the first five dispatched RMC trucks from the batch plant is determined and the departing time for the rest of trucks is determined by the simulation process according to the dispatching sequence generated by the BCO. Table 4 shows an example of the dispatching sequence generated by the BCO. The simulation process starts with the first dispatched RMC truck which departs from the batch plant at 07:30 h. Table 5 records the process of the simulation according to Eq. 6-12 and Table 6 shows the simulated result according to the dispatching sequence and simulation process.

$$
\begin{aligned}
& \mathrm{SDT}_{\mathrm{i}}=\left\{\begin{array}{cc}
\mathrm{IDT}_{\mathrm{i}}, & \text { if } \mathrm{i} \leq \mathrm{c} \\
\mathrm{SDT}_{\mathrm{i}-1}+\mathrm{MD}_{\text {index (i) }}, & \text { if } \mathrm{c}<\mathrm{i} \leq \mathrm{N} \text { and } \mathrm{TBB}_{1} \leq \mathrm{STD}_{\mathrm{i}-1} \\
\mathrm{TBB}_{1}+\mathrm{MD}_{\text {index (i) }}, & \text { if } \mathrm{c}<\mathrm{i} \leq \mathrm{N} \text { and } \mathrm{TBB}_{1}>\mathrm{STD}_{\mathrm{i}-1}
\end{array}\right. \\
& \mathrm{TAC}_{\mathrm{ji}}=\mathrm{SDT}_{\mathrm{i}}+\mathrm{TDG}_{\mathrm{j}} \\
& \mathrm{PTF}_{\mathrm{ji}}=\mathrm{SCT}_{\mathrm{j}} \text { or } \mathrm{LT}_{\mathrm{j}(\mathrm{k}-1)} \\
& \mathrm{WC}_{\mathrm{ji}}=\mathrm{PTF}_{\mathrm{ji}}-\mathrm{TAC}_{\mathrm{ji}} \\
& \mathrm{LT}_{\mathrm{ji}}=\mathrm{TAC}_{\mathrm{ji}}+\mathrm{WC}_{\mathrm{ji}}+\mathrm{CD}_{\text {index (i) }}, \quad \text { if } \mathrm{WC}_{\mathrm{ji}} \geq 0 \\
& \mathrm{LT}_{\mathrm{ji}}=\mathrm{TAC}_{\mathrm{ji}}+\mathrm{CD}_{\text {index (i) }}, \quad \text { if } \mathrm{WC}_{\mathrm{ji}}<0 \\
& \mathrm{TBB}_{\mathrm{i}}=\mathrm{LT}_{\mathrm{ji}}+\mathrm{TDB}_{\mathrm{j}}
\end{aligned}
$$

Where:

$\mathrm{SDT}_{\mathrm{i}}=$ The simulated departing time of $\mathrm{i}^{\text {th }}$ dispatched truck

$\mathrm{TAC}_{\mathrm{ji}}=$ The time that $\mathrm{i}^{\text {th }}$ dispatched truck arrives at construction site $\mathbf{j}$

$\mathrm{PTF}_{\mathrm{ji}}=$ The start pouring time of the construction $\mathrm{j}$ if $\mathrm{i}^{\text {th }}$ dispatched truck is the first truck arrives at construction site $\mathrm{j}$ or the time that the $(\mathrm{k}-1)^{\text {th }}$ truck leaves the construction site $\mathrm{j}$, if $\mathrm{i}^{\text {th }}$ dispatched truck is the $\mathrm{k}^{\text {th }}$ truck arrives at the construction site $\mathrm{j}$

$\mathrm{WC}_{\mathrm{ji}}>0=$ The duration that $\mathrm{i}^{\mathrm{th}}$ dispatched truck waits at the construction site $\mathrm{j}$

$\mathrm{WC}_{\mathrm{ji}}<0=$ The duration that construction site $\mathrm{j}$ waits for the arrival of the $i^{\text {th }}$ dispatched truck

$\mathrm{LT}_{\mathrm{ji}} \quad=$ The time that the $\mathrm{i}^{\text {th }}$ RMC truck leaves construction site $\mathrm{j}$

TBBi = The time that the $i^{\text {th }}$ dispatched RMC truck back to the batch plant

$\mathrm{j}=$ The index of the designated construction site, $\mathrm{j}=1-\mathrm{m}$.

$\mathrm{k}=$ The order of the RMC truck arrives at the respective construction site, $\mathrm{k}=1-\mathrm{k}_{\mathrm{j}}$ for each construction site $\mathrm{j}$

$1=$ The order of the truck that is back to the batch plant and has not been dispatched

c $=$ The number of the RMC trucks that the batch plant owns

Step 3: Determine the fitness value. From the Table 5, the total duration that RMC trucks wait at construction sites and total duration that construction sites wait for the arrival of RMC trucks are 88 and 322 min, respectively. 
Am. J. Engg. \& Applied Sci., 3 (1): 7-14, 2010

Table 5: Simulation results of dispatched sequence

\begin{tabular}{|c|c|c|c|c|c|c|c|c|c|c|c|c|}
\hline \\
\hline $\bar{i}$ & 1 & 2 & 3 & 4 & 5 & 6 & 7 & 8 & 9 & 10 & 11 & 12 \\
\hline $\mathrm{j}$ & 2 & 1 & 3 & 1 & 3 & 2 & 3 & 3 & 2 & 1 & 3 & 2 \\
\hline $\mathrm{k}$ & 1 & 1 & 1 & 2 & 2 & 2 & 3 & 4 & 3 & 3 & 5 & 4 \\
\hline $\mathrm{SDT}_{\mathrm{i}}$ & $07: 30$ & 07:40 & $07: 50$ & $07: 58$ & 08:08 & $08: 56$ & 09:06 & 09:16 & $10: 00$ & $10: 10$ & $10: 18$ & $11: 16$ \\
\hline $\mathrm{TAC}_{\mathrm{ji}}$ & $07: 54$ & 08:10 & 08:35 & $08: 28$ & 08:53 & 09:20 & 09:51 & 10:01 & $10: 24$ & $10: 40$ & $11: 03$ & $11: 40$ \\
\hline $\mathrm{PTF}_{\mathrm{ji}}$ & 08:00 & 08:00 & $08: 30$ & $08: 30$ & 09:20 & $08: 35$ & $09: 25$ & $10: 36$ & 09:41 & 08:46 & $11: 21$ & 10:59 \\
\hline$W_{\mathrm{ji}}$ & 6 & -10 & -5 & 2 & 27 & -45 & -26 & 35 & -43 & -154 & 18 & -41 \\
\hline $\mathrm{LT}_{\mathrm{ji}}$ & $08: 35$ & 08:30 & 09:20 & $08: 46$ & $09: 25$ & 09:41 & $10: 36$ & $11: 21$ & $10: 59$ & 11:00 & $11: 57$ & $12: 15$ \\
\hline $\mathrm{TBB}_{\mathrm{i}}$ & 08:51 & 08:50 & 09:50 & 09:06 & 09:55 & 09:57 & 11:06 & 11:51 & $11: 15$ & $11: 20$ & $12: 27$ & $12: 31$ \\
\hline
\end{tabular}

Table 6: Simulated results generated based on the dispatching sequence

\begin{tabular}{lllllll}
\hline Site (j) & Arrival order (k) & 1 & 2 & 3 & 4 & 5 \\
\hline 1 & Arrival time & $08: 10$ & $08: 28$ & $10: 40$ & & \\
& Departure time & $08: 30$ & $08: 46$ & $11: 00$ & & \\
& Waiting duration (truck) & 0 & 2 & 0 & & \\
& Waiting duration (Site) & 10 & 0 & $154 *$ & & \\
2 & Arrival time & $07: 54$ & $09: 20$ & $10: 24$ & $11: 40$ & \\
& Departure time & $08: 35$ & $09: 41$ & $10: 59$ & $12: 15$ & \\
& Waiting duration (truck) & 6 & 0 & 0 & 0 & \\
& Waiting duration (site) & 0 & 45 & 43 & 41 & \\
& Arrival time & $08: 35$ & $08: 53$ & $09: 51$ & $10: 01$ & $11: 03$ \\
& Departure time & $09: 20$ & $09: 25$ & $10: 36$ & $11: 21$ & $11: 57$ \\
& Waiting duration (truck) & 0 & 27 & 0 & 35 & 18 \\
& Waiting duration (site) & 5 & 0 & 26 & 0 & 0 \\
\hline
\end{tabular}

The interruption of pouring concrete occurs when the duration that the construction site waits for the arrival of the RMC truck is longer than the allowable buffer duration. As shown in Table 5, the number of interruptions marked as $*$ in the Table 5 is one. Since the interruptions of pouring concrete should be avoided, the penalty function is defined as Eq. 13:

$\mathrm{P}=($ the number of interruptions $) \times 60 \times 24$

The interim fitness value $(\mathrm{F})$ of a dispatched schedule is defined as $\mathrm{F}=\mathrm{P}+\mathrm{TWC}$, where TWC is the total duration that RMC trucks wait at the construction sites. In this example, the interim fitness value of the dispatching schedule is equal to $1528(=1 \times 60 \times 24+88)$.

\section{RESULTS AND DISCUSSION}

To assess the feasibility of the BCO method, it has been applied to test on two case studies and is compared with GA and TS. All methods are performed 30 trials, under the same evaluation function and individual definition, in order to compare their solution quality, convergence characteristic and computation efficiency. The software was implemented using MatLab $^{\circledR}$ languages on Intel $^{\circledR}$ Core2 Duo $1.66 \mathrm{GHz}$ Laptop with 2 GB RAM under Windows XP.

Case 1: The example as described in the solution structure. Table 1 shows the information related to this dispatching operation. There are $27720(=12 ! /(3 ! 4 ! 5 !))$
Table 7: Schedule of trucks after RMC dispatching of case 1

\begin{tabular}{|c|c|c|c|c|}
\hline Arrive at plant & Go to site & Arrive at site & Leave from site & Return to plant \\
\hline Truck ID = 1 & \multicolumn{4}{|c|}{ No. of delivery $=2$} \\
\hline 07:30 & 1 & 08:00 & 08:16 & 08:36 \\
\hline 08:44 & 3 & 09:29 & 10:05 & $10: 35$ \\
\hline Truck ID $=2$ & \multicolumn{4}{|c|}{ No. of delivery $=3$} \\
\hline $07: 36$ & 2 & 08:00 & $08: 21$ & $08: 35$ \\
\hline 08:54 & 1 & $09: 24$ & 09:44 & 10:04 \\
\hline $10: 14$ & 3 & $10: 59$ & 11:06 & $11: 36$ \\
\hline Truck ID $=3$ & \multicolumn{4}{|c|}{ No. of delivery $=2$} \\
\hline $07: 46$ & 3 & $08: 31$ & 09:16 & 09:46 \\
\hline 09:56 & 2 & $10: 20$ & 10:55 & $11: 11$ \\
\hline Truck ID $=4$ & \multicolumn{4}{|c|}{ No. of delivery $=3$} \\
\hline $07: 56$ & 1 & $08: 26$ & 08:46 & 09:06 \\
\hline 09:16 & 2 & 09:40 & $10: 15$ & $10: 31$ \\
\hline $10: 41$ & 3 & $11: 26$ & $12: 11$ & $12: 41$ \\
\hline Truck ID $=5$ & \multicolumn{4}{|c|}{ No. of delivery $=2$} \\
\hline 08:06 & 2 & 08:30 & 09:05 & 09:21 \\
\hline $09: 31$ & 3 & $10: 16$ & 11:01 & $11: 31$ \\
\hline
\end{tabular}

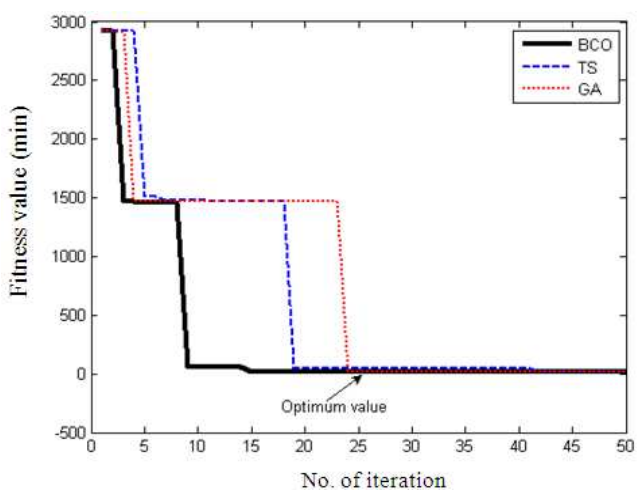

Fig. 4: Convergence characteristics of all methods for case 1

different dispatching schedules. After 30 trials, the best solutions $=[1,2,3,1,2,3,1,2,3,2,3,3]$. The total waiting duration of the optimal dispatching schedule that does not interrupt pouring operation is $2 \mathrm{~min}$.

Furthermore, the program reports the schedule of each truck as shown in Table 7. Fig. 4 shows the convergence curve of searching which converge to the optimal solution. Fig. 5 shows the distribution outlines of the best solution of each trial. The statistic results based on 30 trials, such as the generation cost, standard deviation, computational time and percentage of approaching optimal solution, are shown in Table 8. 
Am. J. Engg. \& Applied Sci., 3 (1): 7-14, 2010

Table 8: Performance comparison of case 1

\begin{tabular}{|c|c|c|c|c|c|c|}
\hline Methods & $\begin{array}{l}\text { Max cost } \\
(\min )\end{array}$ & $\begin{array}{l}\text { Average cost } \\
(\mathrm{min})\end{array}$ & $\begin{array}{l}\text { Min cost } \\
(\mathrm{min})\end{array}$ & SD & $\begin{array}{l}\text { CPU time } \\
(\mathrm{sec})\end{array}$ & $\begin{array}{l}\text { Get optimum } \\
(\%)\end{array}$ \\
\hline GA & 12.00 & 3.20 & 2.00 & 2.02 & 48.96 & 50.00 \\
\hline TS & 12.00 & 3.43 & 2.00 & 3.04 & 37.19 & 70.00 \\
\hline $\mathrm{BCO}$ & 2.00 & 2.00 & 2.00 & 0.00 & 11.04 & 100.00 \\
\hline
\end{tabular}

Table 9: Schedule of trucks after RMC dispatching of case 2

\begin{tabular}{|c|c|c|c|c|}
\hline Arrive at plant & Go to site & Arrive at site & Leave from site & Return to plant \\
\hline Truck ID = 1 & \multicolumn{4}{|c|}{ No. of delivery $=5$} \\
\hline 07:30 & 1 & 08:00 & $08: 20$ & 08:40 \\
\hline 08:50 & 2 & 09:14 & $09: 49$ & 10:05 \\
\hline $10: 20$ & 2 & $10: 44$ & $11: 19$ & $11: 35$ \\
\hline $11: 45$ & 2 & 12:09 & $12: 44$ & $13: 00$ \\
\hline $13: 10$ & 3 & $13: 55$ & $14: 00$ & $14: 30$ \\
\hline Truck ID $=2$ & \multicolumn{4}{|c|}{ No. of delivery $=5$} \\
\hline 07:40 & 2 & 08:04 & 08:39 & $08: 55$ \\
\hline 09:05 & 1 & $09: 35$ & $09: 55$ & $10: 15$ \\
\hline $10: 30$ & 3 & $11: 15$ & $12: 00$ & $12: 30$ \\
\hline $12: 40$ & 2 & 13:04 & $13: 39$ & $13: 55$ \\
\hline 14:05 & 3 & $14: 50$ & $15: 10$ & $15: 40$ \\
\hline Truck ID $=3$ & \multicolumn{4}{|c|}{ No. of delivery $=4$} \\
\hline 07:50 & 1 & $08: 20$ & $08: 40$ & 09:00 \\
\hline 09:15 & 3 & $10: 00$ & $10: 45$ & $11: 15$ \\
\hline $11: 25$ & 3 & $12: 10$ & $12: 55$ & $13: 25$ \\
\hline $13: 35$ & 3 & $14: 20$ & $15: 05$ & $15: 35$ \\
\hline Truck ID $=4$ & \multicolumn{4}{|c|}{ No. of delivery $=5$} \\
\hline 08:00 & 3 & $08: 45$ & 09:30 & $10: 00$ \\
\hline 10:10 & 1 & $10: 40$ & 11:00 & $11: 20$ \\
\hline $11: 27$ & 2 & $11: 51$ & $11: 58$ & $12: 14$ \\
\hline $12: 24$ & 3 & 13:09 & $13: 54$ & $14: 24$ \\
\hline $14: 30$ & 3 & $15: 15$ & $15: 42$ & $16: 12$ \\
\hline Truck ID $=5$ & \multicolumn{4}{|c|}{ No. of delivery $=5$} \\
\hline 08:06 & 1 & $08: 36$ & $08: 52$ & 09:12 \\
\hline $09: 25$ & 2 & 09:49 & $10: 24$ & $10: 40$ \\
\hline $10: 50$ & 1 & $11: 20$ & $11: 40$ & $12: 00$ \\
\hline $12: 10$ & 3 & $12: 55$ & 13:00 & $13: 30$ \\
\hline $13: 45$ & 2 & 14:09 & $14: 44$ & $15: 00$ \\
\hline
\end{tabular}

Case 2: The information of the dispatching operation is the same as used in the case 1 , but the required amount of the RMC $\left(\mathrm{m}^{3}\right)$ is twice of the case 1 . Therefore, $R_{\mathrm{j}}=$ $[28,36,48]$. There are $5.89 \times 10^{9}(=24 ! /(6 ! 8 ! 10 !))$ different dispatching schedules. After 30 trials, the best solutions $=[1,2,1,3,1,2,1,3,2,1,2,3,1,3,2,2,3$, $3,2,3,3,2,3,3]$. The total waiting duration of the optimal dispatching schedule that does not interrupt pouring operation is $19 \mathrm{~min}$. Furthermore, the program reports the schedule of each truck as shown in Table 9. The statistic results based on 30 trials are shown in Table 10.

In the both cases, the best solutions of three methods (BCO, TS and GA) are given in Table 8 and 10 after 30 trials. The results of the BCO method are then compared with those obtained by GA and TS in terms of maximum, average and minimum generation cost, the standard deviation and average computational time. Obviously, all methods have succeeded in finding the optimum solution with a high probability of satisfying the equality and inequality constraints.
Table 10: Performance comparison of case 2

\begin{tabular}{|c|c|c|c|c|c|c|}
\hline Methods & $\begin{array}{l}\text { Max. cost } \\
\text { (min) }\end{array}$ & $\begin{array}{l}\text { Average cost } \\
(\mathrm{min})\end{array}$ & $\begin{array}{l}\text { Min. cost } \\
\text { (min) }\end{array}$ & SD & $\begin{array}{l}\text { CPU time } \\
(\mathrm{sec})\end{array}$ & $\begin{array}{l}\text { Get optimum } \\
(\%)\end{array}$ \\
\hline$\overline{\mathrm{GA}}$ & 112.00 & 34.90 & 19.00 & 27.53 & 44.59 & 66.67 \\
\hline TS & 74.00 & 25.33 & 19.00 & 13.18 & 32.45 & 76.67 \\
\hline $\mathrm{BCO}$ & 32.00 & 19.50 & 19.00 & 2.39 & 10.34 & 93.33 \\
\hline
\end{tabular}

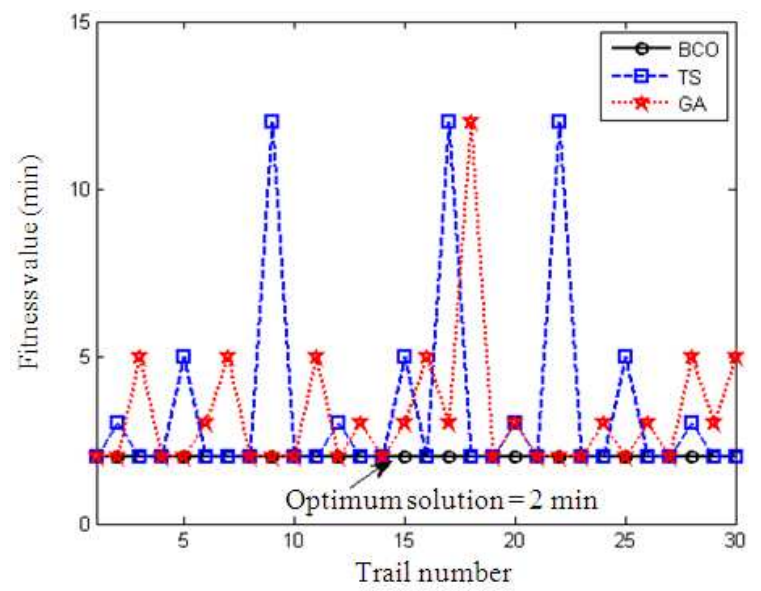

Fig. 5: Distribution of fitness values of all methods for case 1

In order to demonstrate the efficiency of the $\mathrm{BCO}$ method, the distribution outlines of the best solution of each trial are considered. Figure 5 shows the distribution outlines of the best solution of each trial in case 1 . Almost all fitness costs obtained by the $\mathrm{BCO}$ method are lower. This confirms that the BCO method has better quality of solution. Moreover, the convergence characteristics of the BCO method compared with other methods are shown in Fig. 4. The convergence of the $\mathrm{BCO}$ to the optimum solution is faster than other methods.

\section{CONCLUSION}

Efficiently delivering RMC to the construction site is an important issue to the RMC batch plant manager. The batch plant manager has to quickly generate a dispatching schedule that meets the requests from construction sites. However, to handle such an operation is not an easy task and mainly depends on the experiences of the managers in practice. This study presents a systematic approach to modeling the process of dispatching RMC trucks. Results show that by applying the proposed RMC dispatching model to the mechanism which incorporates the $\mathrm{BCO}$ and the simulation technique, the batch plant manager can quickly generate the efficient and flexible dispatching schedule of the RMC trucks, which not only improves 
the operations at the batch plant but also promotes the service of the RMC batch plant.

\section{REFERENCES}

Aarts, E. and J. Korst, 1989. Simulated Annealing and Boltzmann Machines: A Stochastic Approach to Combinatorial Optimization and Neural Computing. Wiley, New York, ISBN: 10: 0471921467, pp: 284.

Bland, J.A. and G.P. Dawson, 1991. Tabu search and design optimization. Comput. Aid. Des., 23: 195-201. DOI: 10.1016/0010-4485(91)90089-F

Cheng, T.M. and C.W. Feng, 2003. An effective simulation mechanism for construction operations. Automat. Construct., 12: 227-244. DOI: 10.1016/S0926-5805(02)00086-9

Dorigo, M., V. Maniezzo and A. Colorni, 1996. Ant system: Optimization by a colony of cooperative agents: IEEE Trans. Syst., Man, Cybernet. Part B: Cybernet., 26: 29-41. DOI: 10.1109/3477.484436

Eberhart, R. and J. Kennedy, 1995. A new optimizer using particle swarm theory. Proceeding of the 6th Proceeding of the Symposium on Micro Machine and Human Science, Oct. 4-6, IEEE Xplore Press, Nagoya, Japan, pp: 39-43. DOI: 10.1109/MHS.1995.494215

Feng, C.W., T.M. Cheng and H.T. Wu, 2004. Optimizing the schedule of dispatching RMC trucks through genetic algorithms. Automat. Cons., 13: 327-340.

http://cat.inist.fr/?aModele $=$ afficheN\&cpsidt $=1560$ 3804

Gen, M. and R. Cheng, 1999. Genetic Algorithms and Engineering Optimization. Wiley- Interscience, New York, ISBN: 10: 0471315311, pp: 512.

Glover, F., 1989. Tabu search-part I. ORSA J. Comput., 1: 190-206.

http://www.cds.caltech.edu/ shiling/Tabu\%20Sear ch\%20Part\%20I.pdf

Glover, F., 1990. Tabu search-part II. ORSA J. Comput., 2: 4-32. 2. http://leedsfaculty.colorado.edu/glover/TS\%20\%20Part\%20II-ORSA.pdf

Goldberg, D.E., 1989. Genetic Algorithms in Search: Optimization and Machine Learning. 1st Edn., Addition-Wesley, Reading, MA., ISBN: 10: 0201157675, pp: 432.
Holland, J.H., 1975. Adaptation in Natural and Artificial Systems: An Introductory Analysis with Applications to Biology, Control and Artificial Intelligence. University of Michigan Press, Ann Arbor, Michigan, ISBN: 10: 0472084607, pp: 206.

Karaboga, D., 2005. An idea based on honey bee swarm for numerical optimization. Technical Report. http://mf.erciyes.edu.tr/abc/pub/tr06_2005.pdf

Kennedy, J. and R. Eberhart, 1995. Particle swarm optimization: Proceeding of the IEEE International Conference on Neural Networks, Nov. 27-Dec. 1, IEEE Xplore Press, Perth, WA., Australia, pp: 1942-1948. DOI: 10.1109/ICNN.1995.488968

Lu, M., M. Anson, S.L. Tang and Y.C. Ying, 2003. HKCONSIM: A practical simulation solution to planning concrete plant operations in Hong Kong. J. Construct. Eng. Manage., 129: 547-554. http://cedb.asce.org/cgi/WWWdisplay.cgi?030437 1

Naso, D., M. Surico, B. Turchiano and U. Kaymak, 2004. Genetic algorithms in supply chain scheduling of ready mixed concrete. ERIM report series research in management. http://ideas.repec.org/p/dgr/eureri/30001944.html

Yan, S., W. Lai and M. Chen, 2008. Production scheduling and truck dispatching of ready mixed concrete. Transport. Res. Part E: Logist. Transport. Rev., 44: 164-179. DOI: 10.1016/j.tre.2006.05.001

Zayed, T.M. and D. Halpin, 2001. Simulation of concrete batch plant production. J. Construct. Eng. Manage., 127: 132-141. http://cat.inist.fr/?aModele $=$ afficheN\&cpsidt $=9415$ 13

Zayed, T.M. and I. Minkarah, 2004. Resource allocation for concrete batch plant operation: Case study. J. Cons. Eng. Manage., 130: 560-569. http://cat.inist.fr/?aModele $=$ afficheN\&cpsidt $=1598$ 3889 